\title{
Language Ideologies in the Linguistic Landscape of One University in South Africa
}

\author{
Jane-Francis A. Abongdia \\ John Wankah Foncha \\ Faculty of Education, University of Fort Hare. \\ jabongdia@ufh.ac.za/jfoncha@ufh.ac.za
}

Doi:10.5901/mjss.2014.v5n7p623

\section{Abstract}

This paper explores the language ideologies reflected on the linguistic landscape of one South African university. The main aim of this paper is to show how the language ideology of an institution or a community is reflected on its landscape (signs, billboards, notice boards, buildings). It also argues that there is a mismatch between the language policy put in place and the actual practice. The findings from this study are examined using studies on language ideologies and linguistic landscapes. The paper suggests that the linguistic landscape of an institution or a community should be an actual representation of its people's language practices and should tie or match with the language policy put in place.

Keywords: Linguistic Landscape, Language Ideologies, Language Policy, Language Practices, English, Afrikaans, isiXhosa

\section{Introduction/Background}

This paper reports on a study of the linguistic landscapes of one South African.

It is a longitudinal study that intends to show how the language ideology of an institution is reflected on its landscape (signs, billboards, notice boards, buildings). Although many studies hold that the language practice of a community is revealed through its linguistic landscape (Pavlenko 2002), this may not always be the case because there can be an overlap between the actual linguistic practices of a people and the linguistic landscape.

South Africa is a country with eleven official languages, and a significant number of minority languages. Despite the large number of official languages, English is the dominant language (Dyers 2008) resulting to a preferred shift toward English. Although Afrikaans is still significantly powerful in some domains across the country, English holds the dominant position. The other official languages are IsiZulu, isiXhosa, SeSotho, SeTswana, IsiNdebele, SePedi, Shangaan, SeSwati and TshiVenda. It is a multilingual country with an extraordinary diversity of races, groupings, languages and landscapes. It has the most diverse and accommodating language policy in the world (Bamgbose 2003).

The language policy at this university aims at "ensuring equity, social development and a respect for South Africa's multilingual heritage" (UWC Language Policy 2003).

\section{The aims of this paper}

- To look at the visibility of language within the said University in South Africa.

- To discuss some of the dominant language ideologies that appear on the landscapes and how they are shaped by particular language ideologies.

- To investigate if the policy on paper is visually reflected on the landscape of the university.

\section{Theoretical Framing of the Study}

Theoretically, this paper examines the notions of linguistic landscapes, language policy/practice and language ideologies. Researchers on linguistic landscapes have observed that the language practices of a community is revealed through its language on signage, postal etc. (Shohamy and Gorter 2009). Linguistic landscape according to Landry and Bourhis (1997: 25) is "the language of public road signs, advertising billboards, street names, place names, commercial shop signs, and public signs on governmental buildings". The language and script of a place or country is first identified by the billboards, adverts, and public signs put in place (Pavlenko 2009). These would suggest whether the country is 
monolingual, bilingual or multilingual. However, the study of linguistic landscape is important because it reveals different qualities of urban experiences as well as the expression of language conflicts (Pavlenko 2009). To this effect, Abongdia (2013), Spolsky and Shohamy (2000), Kamwangamalu (2000), Baldauf and Kaplan (2006), and Brumfit (2006) argue that this is not always the case as a mismatch between policy and practice can be reflected on the landscapes. The above definitions as a starting point raise some commonalities that a landscape reflects language use in a community. Ironically, there is a disagreement to an extent that it is not usually the case. This then challenges the ideologies shared by the different authors but at the same time act like a form of support for each other.

Based on the above, Gorter (2008: 1) argues that language is around us, "displayed on shop windows, commercial signs, posters, official notices, traffic signs etc." Most studies on linguistic landscapes have used this concept to describe and analyse language situations. Gorter holds that it may also extend to the description of the history of language or knowledge of languages. This has to do with language in written form in public spaces, what Bourhis and Landry (2002) refer to as language that is visible within a given area or space. For Gorter (2008: 2), linguistic landscape has to do with sign coding scheme with each made up of how the languages appear on the signs, the location of the signs, the font sizes, number of languages used on each sign, order of languages on bilingual or multilingual signs. This view is used as the analytical tool for this paper. Lanza and Woldemariam (2009) look at language ideologies based on Landry and Bourhis' (1997:23) notion of "the visibility and salience of languages on public and commercial signs in a given territory or region". What is interesting here is the different ideologies people hold based on the language policy as well as where they place themselves in a multilingual situation and policy through their Linguistic Landscape contributions (Abongdia 2013 and Lanza and Woldemariam 2009). With regards to the above observation, Shohamy (2006) argues that the public space can be a good setting for ideological battles. She further contends that the presence (or absence) of language(s) displayed in the public spaces communicates a message, "intentional or not, conscious or not, that affects, manipulates or imposes de facto language policy practice" (p. 110). In view of her argument, one can suggest that all the views/perspectives above help to contribute to an understanding of language ideologies within a diverse environment

According to Pavlenko (2009: 248) linguistics landscapes are analysed based on the frequency with which a language appears, the ordering of the language in a bilingual or multilingual context, the relationship between presumed translation equivalents, the prominence of a particular language such as order, font size, colour, spatial location, as well as the mobility of signs. These can be analysed from different theoretical perspectives, and many always come out with the power relations between different groups.

As mentioned earlier, linguistic landscape should be attributed to Landry and Bourhis (1997:24) because they were among the first to identify the relationship between linguistic landscape and language policy. They noticed that language policy does not deal with the notion of linguistic landscape properly. From another perspective, Shohamy (2006:112) observes that it is a mechanism affecting de facto language policy and is a major aspect in manipulating language. From another viewpoint, Spolsky (2009:65) posits that the "public linguistic space" is shaped and controlled consciously by rules and regulations which are the key to language policy. Yet, Pavlenko (2010: 148) holds that changes in linguistic landscape should not only be seen as comprised of reflection of overall language shift, but as a "direct outcome of language changes in political regimes". In a sense, the above views are meant to suggest that the dominant language in use is as a result of its political affiliation to those in power (policy makers).

Du Plessis (2011) on the other hand, refers to linguistic landscape as language visibility. He argues that there is a lack of alignment between the constitutional policy on language use and linguistic visibility back before 1994 that was not corrected by the post 1994 language policy. Focusing on the Free State province, Du Plessis further argues that no explicit policy currently exists. In line with the above, Cenoz and Gorter (2006) observe that one of the ways of analysing language is by focusing on the written information on language signs in a given area. Based on this, linguistic landscapes also reflect the power relations as well as the status of the different languages in the sociolinguistic context (Cenoz and Gorter 2006:67). It also contributes to the construction of sociolinguistic context as the visual language affects and influences people's different linguistic behaviours and language use. The language used on the official language sign can be compared to the language policy of the region. Thus, the signage of any landscape can say a lot about the language ideologies of the people in that given context.

To get a better understanding of the Linguistic landscape and Language planning, Kaplan and Baldauf (1997: 3) attempt to define them as "a body of idea, laws, and regulations (language policy), change, rules, beliefs, and practices intended to achieve a planned change (or to stop change from happening) in the language used in one or more communities. To put it differently, language planning involves deliberate, although not always overt, future oriented change in systems of language code and/or speaking in a societal context". In view of this, Mühlausler (2000) argues that languages are not isolated systems but interact with other systems outside linguistics such as culture, politics, and environment. Based on the above, we argue that language planning on one part of this system somehow affects the other 
in one way or the other either consciously or unconsciously. That is to say that the ideologies of individuals toward a language are in a way influenced by language planning and policy.

Spolsky and Shohamy (2000) from their stand point define language policy as "an effort by someone with or claiming authority to change the language practice (or ideology) of someone else". Thus, the policy maker has some level of authority over those expected to follow the policy. They support Ager (1996) who sees language policy as obtaining power rather than distributing it. Spolsky and Shohamy think that if language policy aims at changing language practice, then there is a concern for studying not just policy making but as well studying the implementation and evaluation of the policy. For policy to be analysed, it becomes very important to evaluate its impacts. It is therefore important to note that sometimes the statement of the policy can be more important than its effective implementation.

In light of the above debates, these writers are of the opinion that ideologies about language are an integral part of ideologies in other domains of human activity such as the creation of language policy. This observation is in accordance with the works on language ideologies by linguistic anthropologists like Kroskrity, Schieffelin, Woolard and Fairclough and sociolinguists like Weber and Horner and Myers-Scotton. We also think it is on these bases that Irvine and Gal (2000) point out that language ideologies are "the ideas with which participants and observers frame their understanding of linguistic varieties and map such understandings onto people, events and activities that are significant to them. These ideologies are not only held by the immediate participants in the local sociolinguistic system but also by observers like linguists and ethnographers, who have put in place, boundaries between people and languages" (Irvin and Gal, 2000:35).

Based on the above, Sociolinguists like Weber and Horner (2012: 16) define language ideology as the "cultural system of idea and feelings, norms and values, which inform the way people think about language". They refer to Kroskristy's (2000) concept of language ideology as representative of perceptions of a language or discourse "constructed in the interest of a specific social group: they are multiple rather than fixed or unitary; people usually display varying degrees of awareness of these language ideologies; and language ideologies mediate between social structures and forms of talk" (Weber and Horner 2012: 16). Weber and Horner (2012: 16-20) list five major language ideologies:

- There is a language hierarchy - language uses can be labelled and divided into 'languages' or 'dialects', 'patois', etc. , with 'languages' enjoying the highest status. Some languages also enjoy a higher status than others when they are labelled national or official languages;

- The standard language ideology (Milroy and Milroy 1999) - based on the belief that languages are internally homogenous, bounded entities, with a certain variety chosen for standardisation simply because of sociopolitical movements, and definitely not because of any inherent superiority of these varieties over others;

- The ideology of language purism, which stipulates what constitutes 'good' and 'bad' language usage, and often appears in times of rapid social change;

- The one-nation one-language ideology, which makes language equal to territory and national identity; and

- The mother-tongue ideology, which believes that speakers only have one mother-tongue.

Weber and Horner conclude that the fear of linguistic heterogeneity and ideologies of purism are not just ideas and attitudes about language but are translated into practices that can lead to social consequences for the entire community. They see languages as determined by socio-political factors rather than purely linguistic ones, resulting in languages being social constructs - means of social interaction. In view of this, we argue that linguistic landscape can be a mismatch with the language policy since language is usually being influenced by socio-political and historical factors.

\section{Methodology}

This paper forms part of Abongdia's doctoral thesis where a qualitative methodology was used to analyse the linguistic landscape of the university under study. The data constitutes part of the data used in her thesis and was collected through observations of the linguistic landscape in and around the university under study. The signs and billboards that we selected, were carefully chosen to reflect the general signage at the university. We collected as many signs as we could while avoiding redundancy, we decided to use representations as the signs were grouped in the form of coding and the most appropriate chosen to represent that category.

Some of the data were also gathered through interviews and open-ended questionnaires. Two sets of questionnaires and interview questions were designed, one for the students and the other for the lecturers. Since we used the qualitative research design, we decided to use lecturers and students from the different language departments (Linguistics, Afrikaans, English and isiXhosa) at the university. This was because they could have an idea on the content of the study as well as notions on language policy and planning. Those interviewed on a face to face encounter were selected students and lecturers from the different language departments depending on their availability. The interviews 
were transcribed and then used as part of the data for this study. We assured that all ethical proceedings were undertaken such that participation was voluntary.

Overall, the data was collected as follows:

1. Attention was paid to signs and billboards on campus and its surroundings- the 'linguistic landscape' in which the students find themselves, which are visual representations of dominant language ideologies (Kroskrity 2000, Kress 2006).

2. Open-ended questions questionnaires and interviews.

\section{Findings and Discussion}

The choice of this university was based on its accessibility to the writers and its multilingual language policy. Thus, our expectation is to see how such anxiety and policy is implemented in this university and whether their signage could be a good reflection of the policy as it may be in practice.

The linguistic landscape of the university revealed a lot on the language practices and the language situation at the institution (Pavlenko 2009). In the interviews with the students and lecturers, some of them made mention of the fact that the three Western Cape languages are not represented on the bill boards and other public notices in and around the campus. Some of the students in this study expected to see the three languages on the same notices: "looking at the signage on campus, you can see that it is predominantly English. I have not seen a lot of English, Afrikaans and Xhosa signs in one place". They felt that because the policy allowed for the use of the other languages out of official lectures, these languages should have been used on the bill boards in order to assist those who were not English first language speakers. It was for such reasons that another student said that: "the 2003 policy approved by the council states that signage will progressively be in Afrikaans, English and Xhosa. If this was implemented then all the signs on campus would be in the three languages". This suggests that the policy was not being implemented as all three languages are not being used on the bill boards and other notices. Therefore, the policy does not match practice (Abongdia 2013, Baldauf and Kaplan 2006 and Brumfit 2006).

The dominant language signage found around the university is English. Although the policy allows for English to be used as the medium of instruction, it also allows the use of other Western Cape languages. One would wonder if everyone reads and understands the notices in English. We wish to caution that the type of multilingualism practiced in this institution is the same like that practiced in South African public spaces. It seems that African countries are keen to put on a policy that is impressive but they tend to fail in actual practice (Abongdia 2013). Upon this observation, we posit that the language policy/signage and social practices of the people are a complete mismatch.

Furthermore, it is evident that all the notices in and around the main buildings are in English. An example is the administrative building where there are four different billboards all in English. It would have been reasonable if a translation of the information was on the other boards in Afrikaans and isiXhosa as well to give everyone a "fair chance", and also to put into practice what is in the policy (Abongdia 2013). It is therefore a justifiably evident that this particular university like South Africa has a good policy on paper that contrasts their social and actual practices. One therefore begins to wonder if it is an African sickness.

It is worth noting that of all the main notices found around the campus, the only translation found on them was "welcome" that is written in the three different languages [welcome, wamkelekile, welkom]. The translation of the greetings concurs with the translation of greetings during graduation ceremonies at this university. This was said by one of the lecturers interviewed to be the only translation that is done in such occasions. Another case is a notice that cautions students only in English not to take food and to switch their phones to silent when they enter the main library. In view of the above, we argue that since English is the default language of teaching and learning, it appears to be needful to put up notices and postal only in English to urge students to try to figure out meaning and by so doing, it becomes a form of social practice that would foster the reading culture. Despite this probability, the signages are indicative of the lack of multilingualism as the institution claims.

In the same light, the University logo with its motto: "A place of quality, a place to grow, from hope to action through knowledge" is in English. One wonders the importance of "welcome" compared to all these other notices. Although one may want to say that this is a representation of the language policy of university (Pavlenko 2009), this might not be the case as evident from interviews with lecturers and students. Ironically, this English hegemony seems to have a positive influence on the students in the sense that they struggle to read and make sense/meaning from the English words and by so doing; they are also learning.

It would be very interesting to share an insight from the Afrikaans and Xhosa departments. The expectation here would be that of a monolingual Afrikaans/Xhosa setting and this was more of the case with an insignificant (2) bilingual 
translations on the doors of some lecturers in the Afrikaans department. In line with the policy, the landscape here revealed a monolingual Afrikaans environment. From some of the notices observed on the Department's notice board. Talking to some of the lecturers present in the department and asking why the notices were mainly in Afrikaans, some of lecturers said that the aim of the department is to encourage and promote the use of Afrikaans. One other lecturer said that the department has a long standing history of Afrikaans only. Taking this into consideration, one may say that this department attempts to follow the language policy of the university. In light of this, it might be worthwhile for the university to use English only on the notices and postal to oblige students to attempt making sense from these readings and therefore learning to read.

It is needful to signpost right from this point that isiXhosa is the language that most of the respondents in this study see as the most relegated Western Cape languages at the institution. In this regard, one may expect the speakers of this language to use and encourage others to use it. In contrast with the Afrikaans department, the signage within the isiXhosa department revealed a monolingual English environment as everything there was in English but for the invitation in the image below that was found on the third visit to the department.

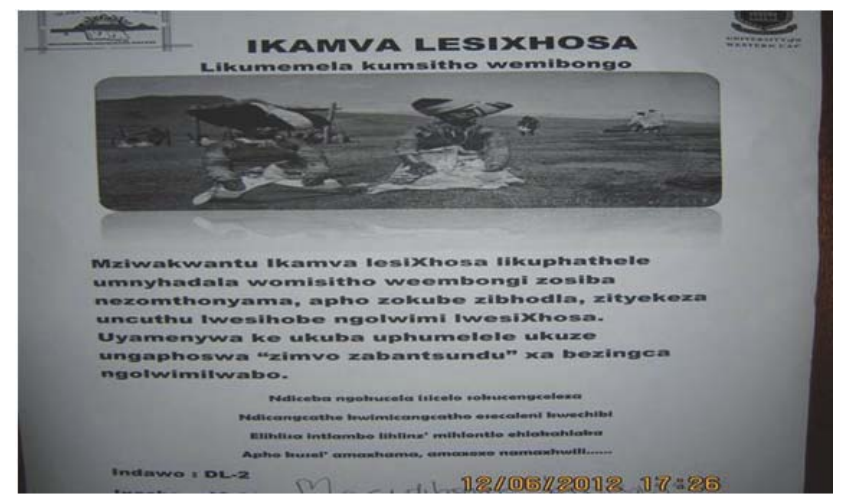

\section{[THE IKAMVA LESIXHOSA ASSOCIATION}

Invites you to a poetry ceremony

Fellow Africans, the Ikamva lesiXhosa Association is hosting a ceremony of modern poetry reading and traditional poetry recitation in isiXhosa. You are cordially invited to this occasion as Africans celebrate their mother tongue.

I contemplate a request to recite

And delicately walk on panels along the lake

Which meanders down the valley and cut through the bushy trees

Where cattle, frogs and hyenas quench their thirst

Venue: DL2]

NB: IKAMVA LESIXHOSA is the name of the association which literally means "The future of isiXhosa." Ironically, when we requested some lecturers and students to translate the text for us, they were unable as they claimed that it was so difficult because it was poetic in nature and written in deep isiXhosa.

As a matter of emphasis, it must be said that this department was visited three times and all the notices were in English but for this one which was found during our third visit. However, the pride in using isiXhosa expressed in the notice also revealed how positive some of the isiXhosa speakers were about their language. It is ironically, intriguing to note that English dominates in the signage of this department despite the complaints about the dominant use of English mostly by the isiXhosa speakers. Our fear is that this appears to indicate a language shift from isiXhosa to English and that this department may cease to exist any time soon.

To draw a conclusion on the dominant use of English in this department, some of the lecturers were as well questioned on the issue of the medium of instruction. Two of the lecturers were of the view that most of the isiXhosa students are not first language speakers of the language and would therefore struggle with notices and instruction in isiXhosa unlike the Afrikaans department. One went further to say that he teaches isiXhosa in English while the other said that she only speaks isiXhosa in her classes, thus, the need to complement this with English notices and readings. The third lecturer on her part justifies the dominant use of English in this department with the fact that there are insufficient teaching materials available in isiXhosa. If one considers the three views above, one may be tempted to say that there is no synergy between the lecturers, and that there is no real medium of instruction in the department. This alone goes a 
long way to justify the different language ideologies held in this department. It is evident that unlike the Afrikaans department where Afrikaans is the dominant language and medium of instruction with the aim of encouraging and motivating the students to learn and use Afrikaans, English is the dominant language in the isiXhosa department and here the aim is to assist the students to understand content and concepts. The question that comes to mind is if this department cannot encourage the study and use of isiXhosa, where else can these students be motivated to use this language? They were supposed to be the department that upholds bilingualism and adhering to the multilingual medium of instruction and language policy of South African.

Despite the arguments put forwards by the lecturers in the Xhosa department, one would still have expected these notices to be written in isiXhosa before having them on the notice boards so as to encourage the students to use the language. Hence, there is a mismatch between policy and practice (Kamwangamalu 2000; Brumfit 2006 and Abongdia 2013). This also contradicts Pavlenko,s (2009) observation that the language policy of an institution is revealed by its linguistic landscape in favour of Shohamy (2006:110) assertion that in a public setting there are ideological battles "intentionally or not, consciously or not, that affects and manipulates or imposes de factor language policy practice". Although isiXhosa is said to be the main language used in this department and their medium of instruction, English is the dominant language in terms of its linguistic landscape. It can be argued here that a language is better learned when exposed to its use and if students are not allowed to read this language and use it then they may hardly be competent in that language.

In the Linguistics Department, all notices were in English with no other language used in their notices despite the department's stated commitment to "multilingualism as a resource for democratic participation and social and political action aimed at developing and empowering individuals and communities" (Department of Linguistics, Research Prospectus 2011:iii). The only other language found in the landscape of the department was Afrikaans only used in the word "Linguistiek" (linguistics) on the notice board. This translation is found on some of the doors of lecturers in the department. One therefore wonders the importance of this word. Also, there is no isiXhosa translation to reflect the language policy of the university as well as tie with the multilingual vision of the department in particular.

Apart from the main notice board (general notice) in the linguistic department, there are sub-notice boards for the different levels. The only English notices within the department contradict the department's objective to encourage multilingualism and empower individuals and communities (Department of Linguistics, Research Prospectus 2011: iii). Although we are against the mismatch between policy and practice, there are advantages as well as disadvantages attached to it. The advantages include; the zeal for the learners to struggle to maintain their languages, the obligation to embrace and use the world's lingua franca and the ability to become employable in public domains. The disadvantages include the marginalization of minority languages in a multilingual context, a shift to the dominant language and possibly the death of some languages.

\section{Conclusion}

It was evident from the study that most of the bill boards around this institution were in English as conspicuously visible in the landscape with an insignificant number of Afrikaans and isiXhosa notices. These findings are in view of language hierarchy (Weber and Horner 2012), with English clearly ranked as the most important language at the university despite the insignificant number of its L1 speakers. In addition, these 'commonsense' positioning (Ricento, 2006) of the English as the most visible language in the Linguistic Landscape of the university also reflects Kroskrity's first dimension of language ideologies: in view that "...language ideologies represent the perception of language and discourse that is constructed in the interest of a specific social or cultural group" (2000:8).

Furthermore, the notion of one-nation-one language of Weber and Horner (2012) also came out, with English being the main language on the billboards in the university. This fails to respect the language policy, Bill of Rights and the South African Constitution. To say this nicely, there is need for an attempt to be made towards actualizing the language policy in practice (Prinsloo 2011). In this regard, the linguistic landscape of this said insitution reveals a mismatch between their language policies and actual practices, and hence shows some evidence of the dominant language ideologies in these spaces, particularly those of the people in charge of the signage - administrators, sign-writers, lecturers and so on.

In addition, the study revealed that the signage at this South African university shows the hierarchy of languages at the university. The dominant language was English, followed by Afrikaans and with very little Xhosa dotted here and there. This revealed a mismatch between policy and practice at this institution, given that the policy undertook to introduce more multilingual signage progressively. Where then is the multilingualism that the university language policy advocates? This would be a resource for the students and the other role-players concerned but they are not taking the advantage attached to it because of the Ricento's notion of the hierarchy of language. However, it can be argued that the 
use of English only helps to foster the learning of the language of instruction as a social practice since students do not have a choice but to read and interpret the English version. In view of this, there are pedagogical implications attached to it in the sense that students are only left with the possibility to interact in their language of instruction (English).

It is important to note that since the onset of globalisation, English has become the lingua franca around the world. Thus a wish to advance commercially and economically in the world of today means a need to speak English (well). The same applies to South Africa as a nation. This may explain why most Xhosa-speaking parents want to place their children in English-speaking schools and why it is important for university students to have a good command of English. It might have been for such reasons that students at this institution are allowed to be able to read and understand the notices and billboards only in English because they are going to have to be able to do so when they leave University and get into the global world.

The implication for this study is to understand the practice of collaborative teaching and learning so that assistance can be provided to support instructor/learners efforts to include multilingual interactions in their courses. In light of this, positive attitude is pursued with an interest of change and improvement. This type of learning acknowledges the interest to contribute to scientific knowledge. As such, it is based on common-sense as well as scientific knowledge as means to improve human practices. The scientific goal of such learning is to create knowledge of the practical that is practical to the practical (Dewey 1936). This is to say that both common-sense and scientific knowledge is meant for human practices that should be useful for management and improvement of practices around them.

Thus, this paper can be seen as an investigation into one or more local practices. In order to develop scientific knowledge, it is necessary to get close to local practices. Many times, such an inquiry is best performed as intervention, where the practicality of knowledge is tried out in actions.

Finally, the main objective for the study of Linguistic landscape is to make sure those practical matters in local practices is to contribute to general practical knowledge. In many situations, this type of learning may also include intervention, of varying degrees, into the studied local practices.

\section{Reference}

Abongdia, J. A. 2013. Language Ideologies in Africa: Comparative Perspectives from Cameroon and South Africa. Unpublished Ph.D thesis. Bellville: University of the Western Cape.

Ager, D. E. 1996. Language Policy in Britain: Varieties of Language and the Language of Varieties. Inaugural Lectures. University of Birmingham.

Baldauf, R. B. and Kaplan, R. B. 2006. Language Policy and Planning in Botswana, Malawi, Mozambique and South Africa: Some Common Issues. In Baldauf, R. B. and. Kaplan R. B. (ed.) Language Policy and Planning in Africa, Vol. 2. Bostwana, Malawi, Mozambique and South Africa. Clevedon: Multilingual Matters.

Bambose, A. 2003. Language Planning in a Multi-ethnic state: the Majority/Minority Dichotomy in Nigeria. Nordic Journal of African Studies 12(1):105-117.

Bourhis R.Y. and Landry, R., 2002. La loi 101 et l'aménagement du paysage linguistique du Quebec. In Bouchard, P. and Bourhis, R.Y. (eds.) L'aménagement Linguistique au Québec: 25 D'application de la Charte de la Lange Francaise. Québec: Publications du Québec (107-132).

Brumfit, C. 2006. A European Perspective on language as Liminality. In Mar-Molinero, C. and Stevenson, P. (eds.) Language ideologies, policies and practices: language and the future of Europe. Palgrave, MacMillan.

Cenoz, J. and Gorter, D. 2006. Linguistic landscape and minority languages. In Gorter, D. (Ed.), Linguistic Landscape: A New Approach to Multilingualism. Clevedon: Multilingual Matters. 67-80.

Department of Linguistics, Research prospectus. 2010. Online: http://www.uwc.ac.za/usrfiles/.../UWC_Ling_Prospectus for_web_FIN.pdf retrieved (2/10/2012)

Du Plessis, T. 2011. Language visibility and language removal: A South African case study in linguistic landscape change. Communicatio: South African Journal for Communication Theory \& Research 37: 194-224.

Dyers, C. 2008a. Truncated Multilingualism or Language Shift? An examination of language use in intimate domains in a new non-racial working class township in South Africa. Journal of Multilingual and Multicultural Development 29.2:110-126.

Dyers, C. 2008b. Language Shift or Maintenance? Factors determining the use of Afrikaans among some township youth in South Africa. Stellenbosch Papers in Linguistics (SPIL) 38: 49-73.

Gorter, D. 2008. Introduction: The Study of the Linguistic Landscape as a new Approach to Multilingualism. International Journal of Multilingualism. 3 (1) 1-7

Irvine, J.T. and Gal, S. 2000. Language Ideology and Linguistic Differentiation. In P. Kroskrity (ed.). Regimes of Language: Ideologies, Polities, and Identity (35-84). Oxford: American Research Press.

Kamwangamalu, N.M. 2000. A new policy, old language practices: Status planning for African languages in a multilingual South Africa. South African Journal of African Languages 20(1): 50-60.

Kaplan, R. B. and Baldauf, R. B. Jr. 1997. Language Planning from Practice to Theory. Clevedon: Multilingual Matters. 
Kress, C. A. 2006. Youth Leader and Youth Development: Connections and questions. New Directions for Youth Development 1(109):45-56.

Kroskristy, P. V. 1999. Language ideologies, language shift, and the imagination of a Western Mono Community: The recontextualization of a Coyote story. In Schieffelin, B. B., Woolard, K. A. and Kroskrity, P. (eds.) Language ideology Vol. 1: Selected papers from the $6^{\text {th }}$ International Pragmatics Conference. Antwerp: International Pragmatics Association (270-289).

Kroskrity, P. 2000. Language Ideological Perspectives. In Kroskity, P. (ed.) Regimes of Language (1-34). Oxford: American Research Press.

Landry, R. and Bourhis, R.Y. 1997. Linguistic Landscape and Ethnolinguistic Vitality: An

Empirical Study. Journal of Language and Social Psychology. 16, 23- 49.

Lanza, E. and Woldemariam, H. 2009. Language ideology and linguistic landscape: Language policy and globalization in a regional capital of Ethiopia. In Shohamy, E. and Gorter, D. (Eds.), Linguistic Landscape: Expanding the Scenery. New York: Routledge (189-205).

Lippi-Green, R. 1997. Language, ideology, and discrimination in the United States. London: Routledge.

Milroy, J. and Milroy, L. 1998. Authority in Language ( $3^{\text {rd }}$ ed). London: Routledge.

Myers-Scotton, C. 2006. Multiple Voices: An Introduction to Bilingualism. Oxford: Blackwell publishing.

Pavlenko, A. 2002. Bilingualism and Emotions. Multilingua 21: 45-78.

Pavlenko, A. 2009. Language Conflict in Post-Soviet Linguistic Landscapes. Journal of Slavic Linguistics 17, 247-274.

Pavlenko, A. 2010. Linguistic landscape of Kyiv, Ukraine: A diachronic study. In Shohamy, E. Ben-Rafael, E. and Barni M. (Eds.), Linguistic Landscape in the City. Bristol: Multilingual Matters. 133-150.

Prinsloo, M. (2011). What counts as English? A paper presented in the Cape Town international conference of literacy from the 19-21 January 2011.

Ricento, T. 2006. Americanization, Language Ideologies and the Construction of European Identities. In Mar-Molinero, C. and Stevenson, P. (eds.) Language Ideologies, Policies and Practices. Language and the future of Europe. Palgrave, MacMillan.

Shohamy, E. 2006. Language Policy: Hidden Agendas and New Approaches. London: Routledge.

Shohamy, E. and Gorter, D. (Eds.) 2009. Linguistic Landscape: Expanding the Scenery. New York: Routledge.

Spolsky, B. 2004. Language Policy. Cambridge: Cambridge University Press.

Spolsky, B. 2009. Language management. New York: Cambridge University Press.

Spolsky, B and Shohamy, E 2000. Language Practice, language Ideology and Language policy: In Lambert, R. D. and Shohamy, E. (eds.) Language Policy and pedagogy. Philadephia: John Benjamins (1- 42).

University of Cape Town - language Policy 2003. Online: http://www.uct.ac.za/downloads/uct.ac.za/about/policies/languagepolicy.doc retrieved 20/05/ 2010.

Weber, J. and Horner, K. 2012. Introducing Multilingualism: A Social Approach. London: Routledge. 